\title{
TRANSFORMAÇÃO NA PAISAGEM DO REASSENTAMENTO RURAL COLETIVO, TRAVESSÃO KM 27, VITÓRIA DO XINGU/PA
}

\author{
Wellington de Pinho Alvarez ${ }^{1}$ \\ Danyelly Feitosa da Costa ${ }^{2}$ \\ Raírys Cravo Herrera ${ }^{3}$
}

\begin{abstract}
RESUMO
O presente trabalho procura fazer uma análise na mudança da paisagem do Reassentamento Rural Coletivo (RRC) localizado no Travessão km 27 do município de Vitória do Xingu/PA, o qual foi construído como maneira de recompensar as famílias ribeirinhas atingidas pela UHE Belo Monte. Para fazer essa análise serão utilizadas imagens de satélite dos anos de 1991, 1997, 2007, 2011 e 2018, e classificados o uso e a cobertura do solo nesses respectivos anos para que possamos compreender a dinâmica atual no local e mostrar que as famílias atualmente utilizam o solo no reassentamento para a prática da agricultura e pecuária, sendo assim as principais modeladoras da paisagem no RRC.
\end{abstract}

Palavras-chaves: Reassentamento. Paisagem. Solo.

\begin{abstract}
The present work seeks to make an analysis of the landscape change of the Collective Rural Resettlement (RRC) located at Travissão km 27 of Vitória do Xingu / PA, which was built as a way to reward the riverside families affected by the Belo Monte HPP. To make this analysis will be used satellite images from the years 1991, 1997, 2007, 2011 and 2018, and classified land use and land cover in these years so that we can understand the current dynamics at the site and show that families currently use resettlement land for agriculture and livestock, thus being the main landscape shapers in the RRC.
\end{abstract}

Keywords: Resettlement. Landscape. Soil.

\section{INTRODUÇÃO}

A Amazônia é vista como um espaço de expansão capitalista, temos como exemplo a exploração da seringa e a abertura de rodovias. O capital financeiro e industrial está voltado para transformar a natureza e para garantir a apropriação dos recursos naturais pelo capital

\footnotetext{
${ }^{1}$ Técnico em Geodésia e Cartografia pelo Instituto Federal de Educação, Ciência e Tecnologia do Pará (IFPA) 2010, cursou Bacharelado e Licenciatura em Geografia pela Universidade Federal do Pará (UFPA) 2011, é Especialista em Gestão Ambiental pela Faculdade São Marcus (FASAMAR) 2011, também é Especialista em Geoprocessamento e Ordenamento Territorial (FASAMAR) 2013, Mestre em Geografia pelo Programa de PósGraduação em Geografia (PPGEO) da Universidade Federal do Pará em 2015. É discente do curso de Doutorado do PPGEO - UFPA. Professor assistente do quadro efetivo da Universidade Federal do Pará no Campus Altamira, desenvolve pesquisas sobre gestão e ordenamento territorial no âmbito da segurança pública, dinâmicas da paisagem e da paisagem cultural na Amazônia. E-mail: walvarez@ufpa.br

${ }^{2}$ É membra do Grupo Desenvolvimento e Dinâmicas Territoriais na Amazônia - GEDTAM e do Laboratório de Estudos das Dinâmicas Territoriais na Amazônia LEDTAM, pesquisadora voluntaria em: Rede de pesquisas Xingu - REDEX, Centro de Formação e Informação Xingu - CEFORM, Projeto de residencia pedagógica e Fundação Amazônia de Amparo a Estudos e Pesquisas - Fapespa. E-mail: danyellyfeitosa @ gmail.com

${ }^{3}$ Bióloga, Professora da Universidade Federal do Pará - UFPA, Faculdade de Ciências Biológicas e do Programa de Biodiversidade e Conservação - PPGBC, ORCID: http://orcid.org/0000-0002-9699-8359. E-mail: rairys@gmail.com.br
} 
mundial. Segundo Alvarez e Herrera (2017), a paisagem se torna alvo de ações, em especial para acomodar as novas demandas do ordenamento territorial, a conversão paisagística acontece para cristalizar as ações no território. Desta maneira tem-se dado o processo com a construção da UHE Belo Monte, transformam o meio sem considerar as dinâmicas locais, os hábitos e costumes dos sujeitos.

A paisagem possui uma dimensão sociocultural do conjunto geográfico estudado, ela é uma projeção da interação dos mais diversos componentes, portanto, apresenta uma manifestação dinâmica, nunca fixa ou eterna. Exemplo de paisagem segundo Pissinati e Archela (2009) é "espaço ocupado e produzido por uma comunidade de cultura singular, que difere as pessoas e até mesmo o uso do solo das demais comunidades vizinhas".

Uma das principais modificações na paisagem são as derrubadas de matas para a construção de empreendimentos de grande porte, por exemplo, Usinas Hidrelétricas, e o desmatamento de florestas para a produção madeireira e produção agropecuarista. Que feitos de maneira desordenada pode ocasionar degradação do solo em grande escala, prejudicando a paisagem local.

No sistema econômico capitalista, segundo Herrera (2016), a natureza é a principal fornecedora de matéria-prima e não se detêm somente dos meios de produção, mas há necessidade de apropriar-se do meio natural. Um dos recursos mais abundante na região é a água, uma ótima fonte para a geração de energia. A construção de hidrelétricas, em especial na Amazônia, ocasiona a retiradas de famílias de áreas a serem atingidas, causando uma desestruturação nas famílias, como aponta Herrera (2016).

\begin{abstract}
A transformação da terra feita pelo capital é sem dúvidas uma das mais perversas mazelas do capitalismo, pois no momento em que a terra deixa de ter seu valor social e passa ter valor como mercadoria, a desestruturação social é algo marcante, ocorrendo a expropriação de inúmeras famílias (HERRERA, 2016, p. 142).
\end{abstract}

Parte das famílias atingidas receberam indenização, outras a Carta de Crédito ou foram remanejadas para reassentamentos. O Estudo de Impacto Ambiental (EIA) e o Projeto Básico Ambiental (PBA) da UHE Belo Monte consideram que a implantação da Usina levaria a obrigatoriamente remanejar as famílias que moram e/ou produzam nas áreas a serem inundadas.

O Projeto de Reassentamento Rural Coletivo surge como uma opção de compensação, buscando a recomposição das atividades e qualidade de vida das famílias afetadas com condições equivalentes ou melhores àquelas que possuíam antes da implantação do empreendimento UHE Belo Monte. 
Foram aplicadas pesquisas de campo para verificar o local da paisagem e como as famílias reassentadas a utilizam. Também se utilizou imagens da paisagem local a fim de estabelecer como variável o uso e cobertura do solo.

\section{METODOLOGIA}

O Projeto de Reassentamento Rural Coletivo (RRC) possui uma área de 2.474,6417 ha, adquirida pela Norte Energia ${ }^{4}$, situada no município de Vitória do Xingu, no Travessão 27, distante a $20 \mathrm{~km}$ da rodovia Transamazônica (BR-230), retratado na figura 1. São 28 lotes com 75 hectares, dos quais 15 hectares estão livres para usos agropecuários e o restante são áreas de reserva legal e áreas de preservação permanente. A seguir apresenta-se, na figura 1, o mapa de localização do RRC-27km.

Figura 1: Mapa de Localização do RRC

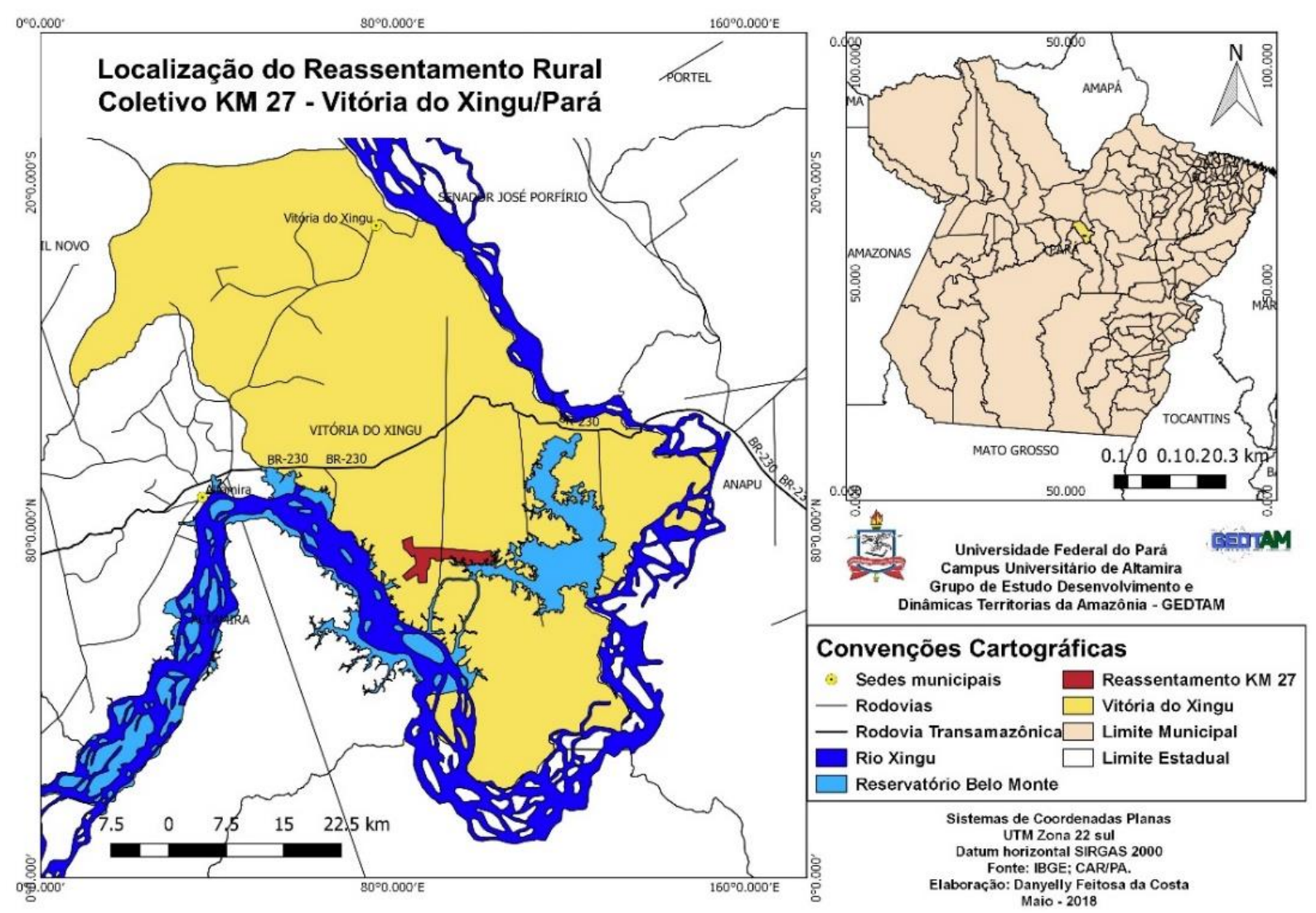

Fonte: GEGTAM/UFPA/Altamira.

A paisagem segundo Bertrand (1971) é o resultado da combinação de elementos físicos, biológicos e antrópicos que reagem dialeticamente uns sobre os outros e "fazem da paisagem um conjunto único e indissociável, em perpétua evolução" (BERTRAND, 1971,

\footnotetext{
${ }^{4}$ Empresa Responsável pela construção de Belo Monte.
} 
p.2). Segundo Alvarez e Herrera (2017), a paisagem manifesta as interações, podendo ser utilizada, gerida e explorada pelas comunidades humanas, por meio da cultura, da técnica ou do capital.

Esse processo de modificação da paisagem mediante o capital é o caso que acontece com a construção da UHE Belo Monte. A área onde está localizado o RRC antes era uma fazenda, uma área voltada ao uso do solo para pastagem. A paisagem do local está em constante modificação, área de floresta à pastagem e, por conseguinte, à área de agricultura, processos estes que afetam o geossistema como um todo. Para analisar a mudança na paisagem iremos utilizar o sistema GTP (Geossistema-Território-Paisagem) de Georges Bertrand, essa metodologia GTP, segundo Pissinati e Archela (2009), não serve somente para delimitar e representar cartograficamente uma área, mas também para detectar problemas existentes no local e o grau de responsabilidade antrópica sobre o mesmo.

A dinâmica na paisagem será analisada através do uso e cobertura do solo nos anos de 1991, 1997, 2007, 2011 e 2018, as escolhas dos anos são referentes aos eventos que marcam esta paisagem. Em 1990 há abertura dos financiamentos para expansão agropecuária na região; em 1997 essa expansão já está em alta; no ano de 2007 ainda era fazenda; no ano de 2011, um ano após o início de construção da UHE Belo Monte, a fazenda já sofreu indenização; e no ano de 2018 completaram-se 3 anos após a chegada das famílias no RRC.

As imagens de satélite foram baixadas no site do Sistema Geológico Americano USGS (http://earthexplorer.usgs.gov), as imagens de 1991, 1997, 2007 e 2011 são imagens do satélite Landsat 5 que possui o sensor TM (Thematic Mapper) sensor este que oferece subsídios para mapeamentos temáticos nas áreas de recursos naturais possuindo uma resolução radiométrica de 8 bits. Já a imagem de 2018 é da cena 22MDB de 22 de julho de 2018 do satélite Sentinel-2A, este satélite faz parte da missão European Space Agency (ESA) desenvolvido no quadro do programa da União Europeia Copernicus e conta com 12 bandas espectrais.

Para a classificação das imagens foi utilizado o software livre Qgis 3.4.7 no complemento Semi-Automatic Plugin (SCP), onde foram definidas 6 classes de uso e cobertura do solo de acordo com os critérios estabelecidos no Manual Técnico de Uso da Terra do IBGE (2013), as classes definidas foram: Áreas antrópicas agrícolas; Áreas antrópicas não agrícolas; Áreas de vegetação natural florestal; Áreas de vegetação natural em regeneração, Água e a classe Cloud, definida pelo autor para classificar nuvens e sombra de nuvens. Cada classe significa os seguintes uso do solo: 
Tabela 1: Classes de uso e cobertura do solo

\begin{tabular}{l|l}
\hline \multicolumn{1}{c|}{ Classe } & \multicolumn{1}{c}{ Uso do solo } \\
\hline Áreas antrópicas agrícolas & Agricultura e pecuária \\
\hline Áreas antrópicas não agrícolas & Estrada e as casas dos lotes \\
\hline Áreas de vegetação natural florestal & Floresta \\
\hline Áreas de vegetação natural em regeneração & Vegetação secundária \\
\hline Água & Canal Belo Monte \\
\hline Cloud & Nuvem e sombra de nuvem \\
\hline
\end{tabular}

Para analisar a evolução da paisagem nos 5 anos, foi feita a medição de cada classe em cada ano através do complemento Calculate Geometry, onde as áreas foram medidas em hectares em cada ano para mostrar a evolução da paisagem e como a mesma se modifica de acordo com o uso que as famílias fazem.

O presente trabalho tem por objetivo analisar a modificação da paisagem e quais os processos que afetam o geossistema, em especial o uso do solo para a agricultura e pastagem que desencadeiam processos que modificam o geossistema como um todo.

\section{RESULTADOS E DISCUSSÕES}

A área atual do RRC sofre com o crescimento rápido de capim, esse processo acontece pelo fato de antes de ser reassentamento, era uma fazenda com grandes áreas de pastagens para pecuária. As famílias reassentadas contam que ao visitarem o local antes de se mudarem, a vegetação existente era apenas pastagens e, quando foram para os lotes, receberam auxílio para a contenção do capim durante um ano por uma empresa a serviço da Norte Energia, pois durante o período de inverno cresce com bastante facilidade, após esse um ano, os meios de intervenção são feitos pelo reassentados.

Os lotes são divididos em duas áreas do reassentamento, conforme apresentado na figura 2, a distribuição apresenta 16 lotes de um lado e no outro estão os 12 lotes restantes. Nas entrevistas realizadas foi detectado um impasse existente entre as famílias reassentadas, alguns apontam que um lado do reassentamento tem o solo bastante fértil para a produção enquanto o outro não. Alguns lotes não estão mais com as famílias reassentadas, pois fizeram a venda, alegando não terem condições de produção na área. As famílias que continuam nos lotes recebem a visita de um técnico de uma empresa a serviço da Norte Energia que os auxiliam para corrigir a terra e preservar as nascentes existentes em alguns dos lotes. 
Figura 2: Reassentamento Rural Coletivo KM 27

Fonte: GEDTAM. Elaboração: Danyelly Feitosa da Costa, 2018.

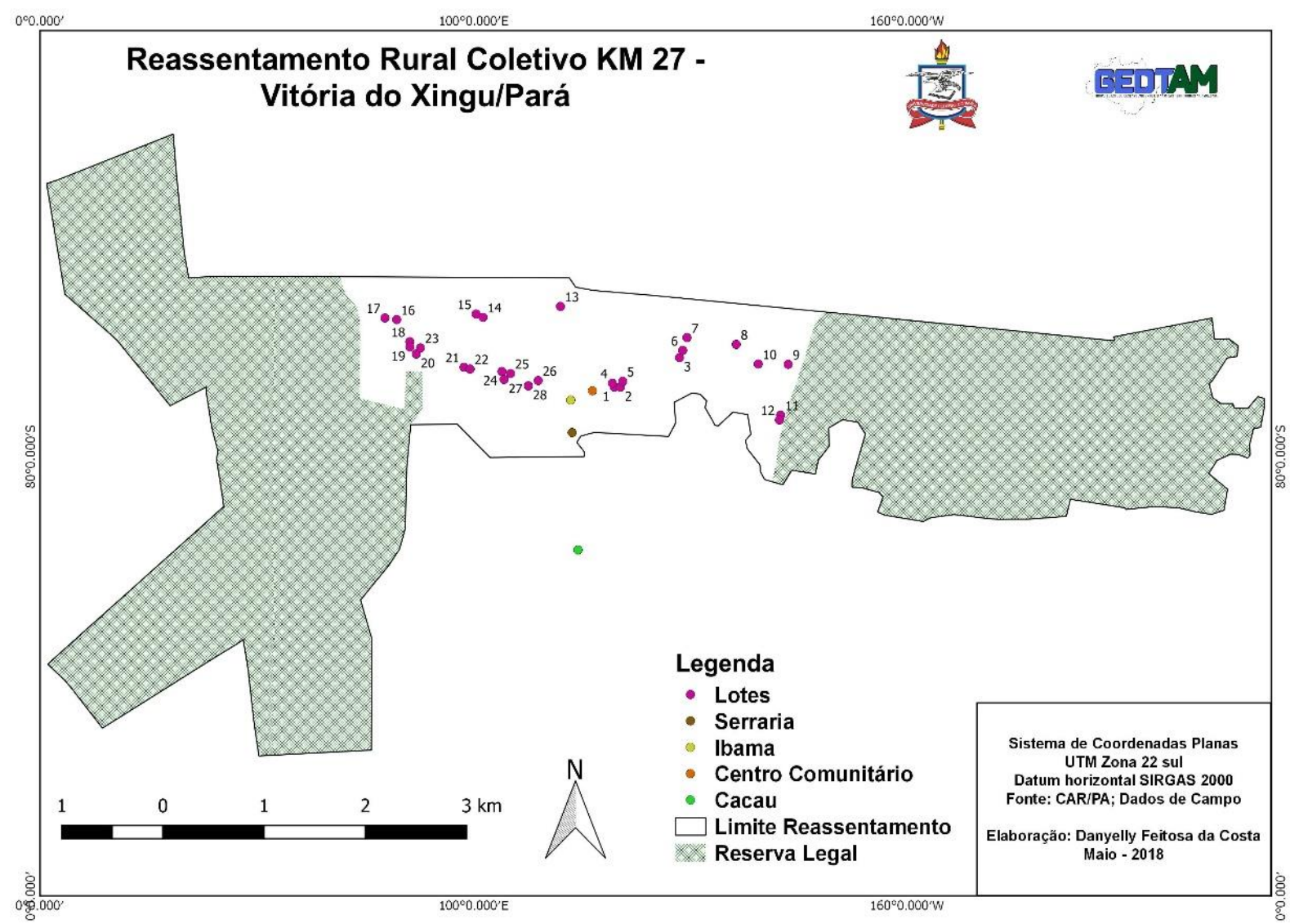

A figura 2 mostra que no RRC possui uma grande área de reserva legal que foi definida em blocos (sistema de condomínios) conectada às áreas de preservação permanente (APPs). Nos estudos realizados pela Norte Energia foram identificados dois sítios arqueológicos que serão preservados para um futuro resgaste dos materiais ali existentes. São destinados 194,5600 ha de APPs e a Reserva Legal em Condomínio possui uma área de 1.770,6600 ha (Norte Energia). É nítido, ao visitar o reassentamento, ver o contraste entre a paisagem natural - a reserva legal - e a paisagem humanizada, aquela que foi transformada pelo homem.

O homem necessita modificar a paisagem natural para atender às suas necessidades, esse processo de modificação é mais nítido na cidade, mas no meio rural acontece por ser modificada para os usos agrícolas, pecuários e florestais do território, assim como, por outros fatores econômicos como estradas, rodovias e usinas. 
Para entender a paisagem local vamos relembrar o processo de ocupação na Amazônia, enfatizando a partir da década de 1970 com a construção da BR-230 (Rodovia Transamazônica). No ano de 1953 houve a necessidade de promover a ocupação e o desenvolvimento socioeconômico da Amazônia, assim o Governo criou a Superintendência do Plano de Valorização Econômica da Amazônia (SPVEA) que foi substituída, em 1966, pela Superintendência do Desenvolvimento da Amazônia (SUDAM), cuja ação é completada pelo Banco da Amazônia e pelo Fundo de Investimentos Privados no Desenvolvimento da Amazônia (FIDAM), os quais tinham como objetivo integrar a região amazônica ao restante do país.

Esses meios criados pelo Governo tinham como intenção “integrar” a Amazônia ao restante do país, mas, além disso, queriam ocupar os espaços vazios (maneira como a Amazônia era vista pelo Governo). Conforme afirma Becker (2015):

\footnotetext{
A ocupação da Amazônia se torna prioridade máxima após o golpe de 1964, quando, fundamentado na doutrina de segurança nacional, o objetivo básico do governo militar torna-se a implantação de um projeto de modernização nacional, acelerando uma radical reestruturação do país, incluindo a redistribuição territorial de investimento de mão de obra, sob forte controle social (BECKER, p. 12, 2015)
}

Assim a Amazônia assume uma posição chave frente às prioridades econômicas e geopolíticas (BECKER, 2015) e dessa maneira eles queriam resolver de forma conjunta os problemas sociais do Nordeste e a continuidade do crescimento do centro dinâmico do Sudeste. Para acelerar esse processo de ocupação foram decididas uma série de medidas vinculadas ao Plano de Desenvolvimentos Socioeconômico do País e ao Programa de Integração Nacional (PIN), por meio do PIN houve o processo de construção da rodovia Transamazônica (BR-230).

A rodovia sai da cidade de Cabedelo-PB e tinha como destino final em Boqueirão da Esperança, a fronteira do Acre com o Peru, onde sua intenção era ligar todo o País e chegar aos portos do Oceano Pacífico como também era uma forma encontrada pelo Governo de colonizar a área que para eles eram espaços vazios. Mas o que de fato aconteceu é que a construção da Transamazônica abriu ainda mais as portas para o capital apropriar-se dos recursos naturais existentes na Amazônia, o que sempre foi visto para a mesma, uma área com enorme potencial de recursos naturais suscetíveis à manipulação por parte de potências internacionais (PORTO-GONÇALVES, 2001).

É necessário lembrar-se deste marco histórico na Amazônia, pois, a partir da rodovia, os espaços nas florestas foram sendo abertos e possíveis de serem explorados com mais 
facilidade, seja pelo capital, como também pela população que ali vai chegando e tomando seu espaço construindo sua vida. A partir de então, o Governo ajudou cada vez mais os proprietários de terra a possuírem mais terra, na década de 1990 a atual área do reassentamento estava com a área de floresta quase intacta, pouco ainda era visível de áreas de pastagens, mas, com o decorrer dos anos e com o financiamento sendo mais fácil para os agricultores, é notório ver esta paisagem sofrer um processo de modificação.

Para entender como a paisagem sofreu modificações ao longo dos anos é essencial compreender como as famílias atualmente modificam-na para a sua sobrevivência no local. A partir disso iremos analisar a figura 4 que mostra a dinâmica na paisagem por meio do uso e cobertura do solo.

Figura 3: Uso e cobertura do solo no RRC nos anos de 1991, 1997, 2007, 2011 e 2018

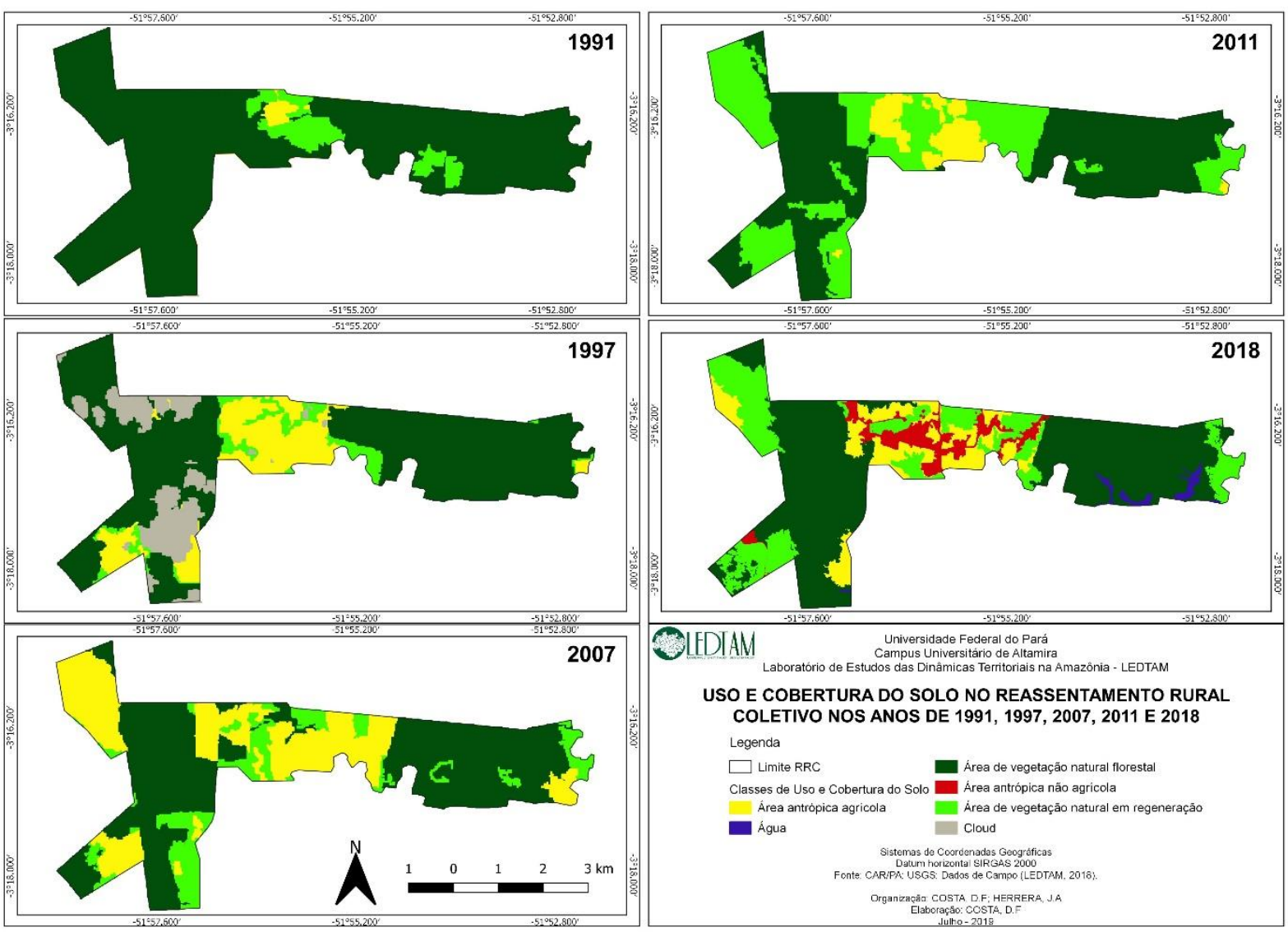

Fonte: LEDTAM. Elaboração: COSTA, D. F, 2019.

A partir da figura 3 é possível perceber que a paisagem no reassentamento passou por grandes modificações que foram influenciadas a partir de 1991, ano em que a paisagem estava com a área de vegetação natural florestal em maior quantidade. A partir de 1997 percebe-se que essa área de vegetação natural florestal foi suprimida e estava sendo ocupada por área antrópica agrícola e em 2007 é mais forte ainda, isso são resquícios de um incentivo bancário 
para os produtores da região de ampliar suas plantações ou pecuária e, como resultado, destruiu-se ainda mais a floresta.

A partir do ano de 2011 é possível perceber que a área de vegetação natural em regeneração está maior, uma explicação para esse motivo é que a fazenda onde está o RRC atualmente está próxima de onde foi construído o canal da UHE Belo Monte e a fazenda já estava em processo de indenização, por esse motivo as áreas antrópicas agrícolas foram abandonadas e a vegetação entrou em processo de regeneração. No ano de 2015 foi implantado o RRC e as famílias começaram a ocupar o local, na imagem de 2018, 3 anos após a chegada das famílias, já mostra o reassentamento consolidado com a presença de uma nova classe, de área antrópica não agrícola, representando o solo exposto onde estão as casas, a estrada e o galpão do IBAMA e da serraria.

Mas o fator crucial para entender a modificação na paisagem do RRC é que as famílias reassentadas acabam se tornando vítimas desse processo de ampliação do capital, são retiradas de suas propriedades, onde mantinham costume e acabam sendo obrigadas a modificar a paisagem local para a sua sobrevivência. As classes onde as famílias modificam essa paisagem são a classe área antrópica agrícola e a não agrícola, nesses dois usos está inclusa a maneira que as famílias utilizam o solo.

$\mathrm{Na}$ figura 4 encontramos o contraste entre duas paisagens dentro de um mesmo geossistema, de um lado observamos a paisagem natural representada pela área de reserva legal e do outro lado a paisagem humanizada, transformada pelo homem, onde vemos o uso do solo para a agricultura com a plantação de bananas. Percebemos como o homem modifica a paisagem para se adaptar ao seu modo de vida e para o seu sustento. 
Figura 4: Contraste de uma paisagem natural com uma paisagem humanizada

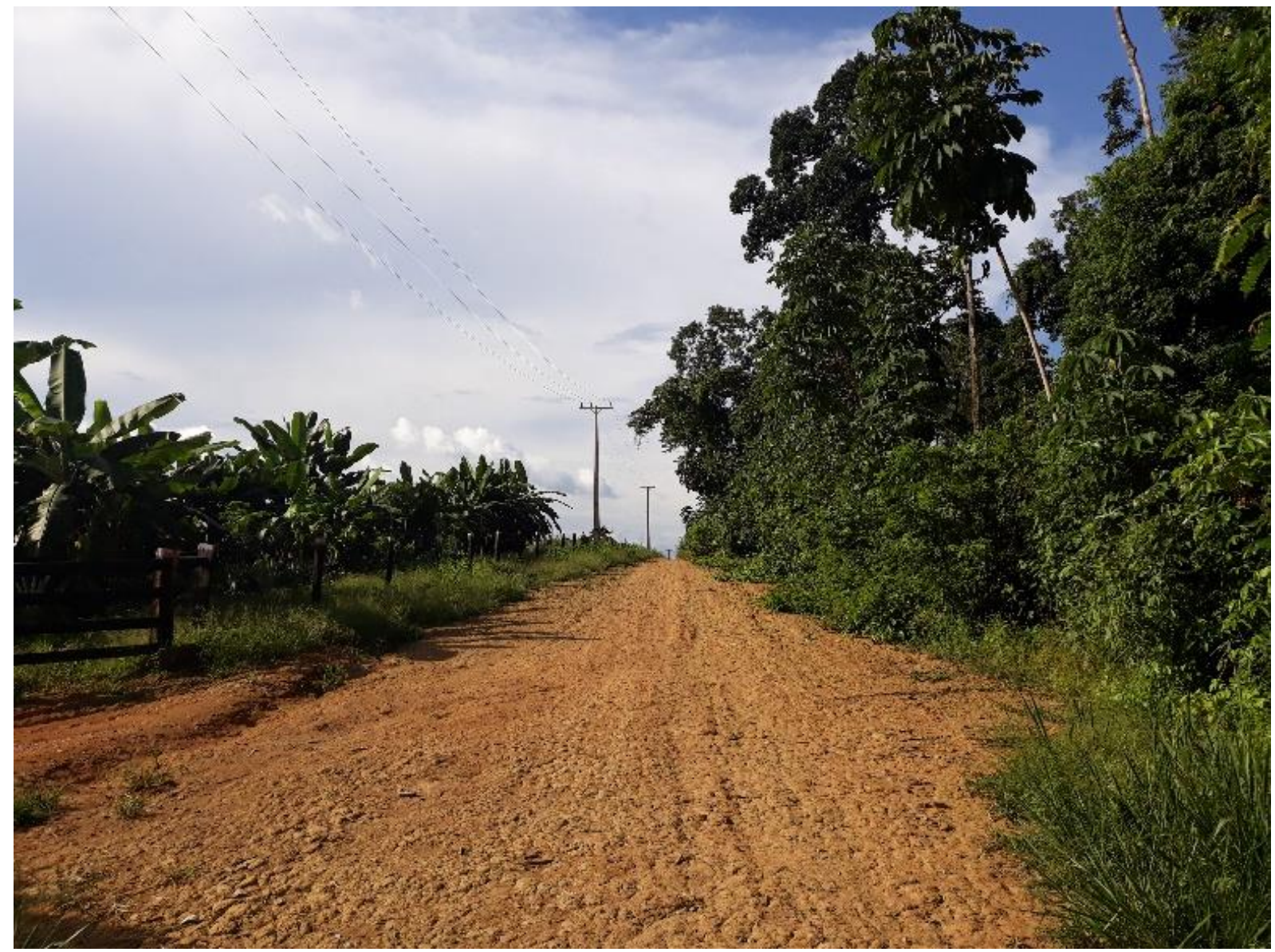

As principais modificações da paisagem rural do RRC são para o uso da agricultura e pecuária. Destaca-se mais a atividade agrícola, dos 28 lotes, 25 deles são para a agricultura e 3 para a pecuária, como demonstrado na tabela 2. Nas idas a campo, em conversa com as famílias reassentadas, observou-se que há um impasse entre eles em relação à fertilidade do solo para o uso agrícola, é apontado que um lado do reassentamento é mais fértil para a produção que o outro. A explicação para que o solo seja pouco fértil é que o solo predominante na área é o Argissolo Vermelho-amarelo distrófico, que segundo a EMBRAPA (2006) é um solo constituído por material mineral, que apresenta em seu horizonte B textura de argila de atividade baixa e apresenta uma baixa fertilidade. $\mathrm{O}$ uso indisciplinado do solo pode causar um desgaste do mesmo, é importante haver uma manutenção na produtividade e na conservação ambiental, desse modo há uma sustentabilidade do agroecossistema. 


\begin{tabular}{c|c|c|c|c|c}
\hline Lotes & $\begin{array}{c}\text { Área uso do solo } \\
(\mathbf{h a})\end{array}$ & Uso do solo & Lotes & $\begin{array}{c}\text { Área uso do solo } \\
\text { (ha) }\end{array}$ & Uso do solo \\
\hline 1 & 15,0881 & Agricultura & 15 & 15,0905 & Agricultura \\
\hline 2 & 16,9277 & Agricultura & 16 & 15,4434 & Agricultura \\
\hline 3 & 17,1747 & Pecuária & 17 & 15,3623 & Agricultura \\
\hline 4 & 15,0007 & Agricultura & 18 & 15,0082 & Agricultura \\
\hline 5 & 15,0245 & Agricultura & 19 & 15,0941 & Agricultura \\
\hline 6 & 17,3182 & Pecuária & 20 & 15,3639 & Agricultura \\
\hline 7 & 17,2944 & Agricultura & 21 & 15,4375 & Agricultura \\
\hline 8 & 16,5375 & Agricultura & 22 & 15,2387 & Agricultura \\
\hline 9 & 15,2407 & Agricultura & 23 & 15,6454 & Pecuária \\
\hline 10 & 16,9284 & Agricultura & 24 & 16,3720 & Agricultura \\
\hline 11 & 15,9694 & Agricultura & 25 & 16,3212 & Agricultura \\
\hline 12 & 15,0447 & Agricultura & 26 & 16,1037 & Agricultura \\
\hline 13 & 15,0645 & Agricultura & 27 & 15,0958 & Agricultura \\
\hline 14 & 15,0731 & Agricultura & 28 & 15,1911 & Agricultura \\
\hline
\end{tabular}

A forte exploração da paisagem na Amazônia aconteceu durante a formação histórica de colonização, onde diversas atividades foram implementadas sem levar em conta os aspectos socioambientais de cada local. Entre estas atividades estão a conversão de terras à exploração agrícola e pecuária, que são as principais áreas atrativas de investimento na região, em seguida vem o setor madeireiro (SOUZA et al., 2012 apud LENTINNI et al., 2005), são esses os fatores que acontecem na Amazônia como um todo, também acaba acontecendo no RRC.

Algumas práticas realizadas no solo podem modificar suas propriedades físicas, em sua grande parte na estrutura, podendo as alterações serem permanentes ou temporárias e ainda podem influenciar os processos erosivos. O solo que é submetido a um cultivo intenso tem a sua estrutura original alterada, tanto em níveis de poros quanto na densidade do solo (CARPENEDO; MIELNICZUK, 1990). 
Figura 4: Plantação de milho em um dos lotes do RRC.

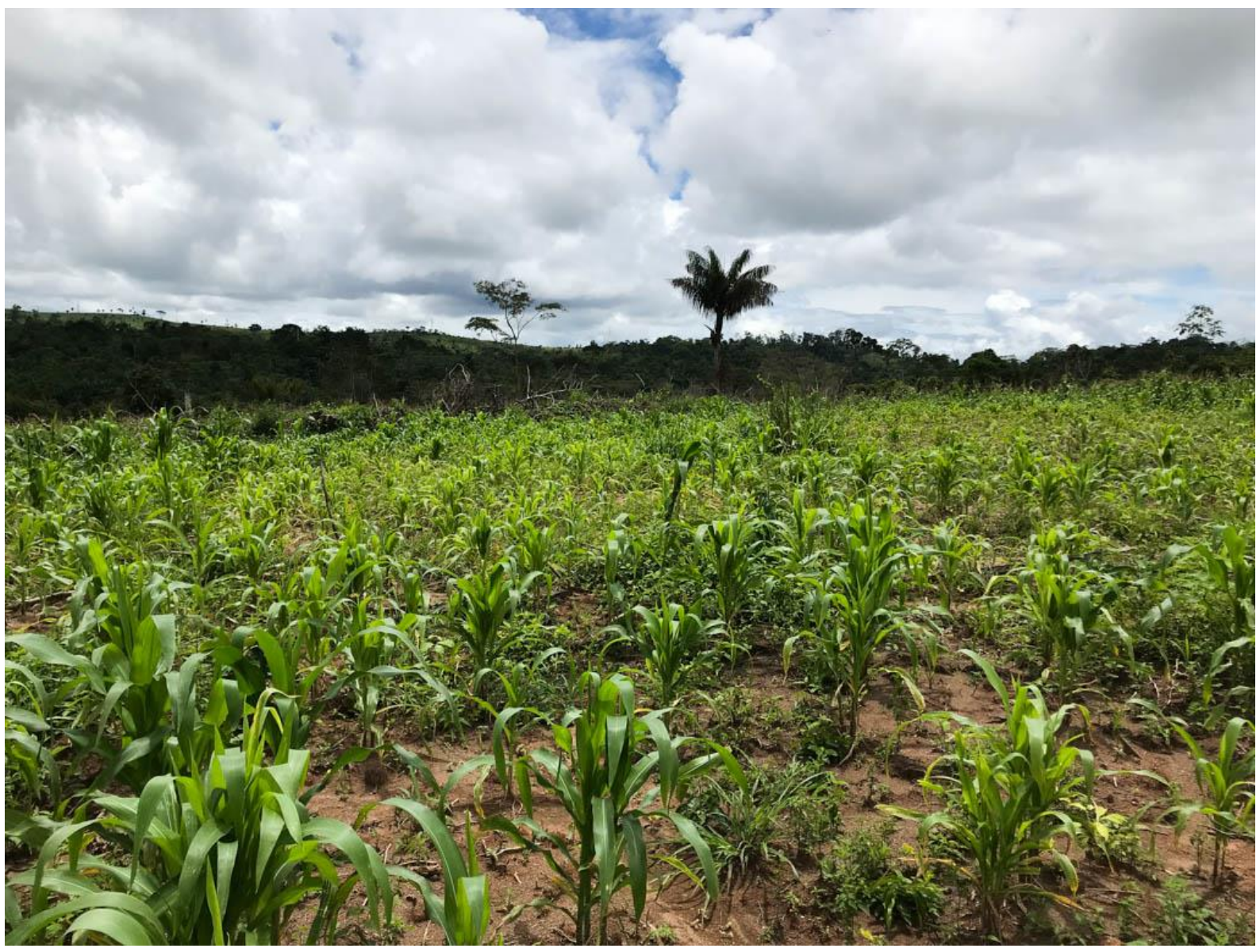

As práticas de monocultura, ou seja, plantar apenas uma espécie de planta em uma grande região contribui para a degradação ambiental, este tipo de cultivo contínuo e prolongado causam mudanças físicas no solo, principalmente na sua porosidade. Para não haver o desgaste do solo é necessária uma rotação de culturas, conservando as estruturas físicas e químicas. No caso do RRC não há a prática de monocultura, a agricultura praticada pelas famílias reassentadas é a de subsistência, a qual tem por objetivo a produção de alimentos para a sobrevivência do agricultor, sua família e comunidade. Os principais cultivos realizados são cacau, mandioca, macaxeira, banana, milho, limão e laranja.

A atividade pecuarista causa impactos sobre o meio ambiente, dentre eles a degradação do solo e a perda de biodiversidade. A produção animal interage com o meio ambiente seja pela alimentação ou pela dessedentação. Os impactos ambientais dessa produção são proporcionais à relação entre a intensidade com que a mesma é praticada e a disponibilidade de recursos naturais.

O processo de remoção da vegetação arbórea para a formação de pastagens, além de comprometer a biodiversidade, também compromete o ciclo da água, pois reduz a infiltração e 
o armazenamento, libera gás carbônico para atmosfera contribuindo para a mudança climática, aumenta a velocidade de lixiviação, ocasionando a compactação e erosão no solo.

Essa atividade ainda afeta a reposição de água doce através da compactação do solo, o que acaba diminuindo a infiltração para os lençóis freáticos e a degradação das margens dos rios. Prejudica as nascentes que estão bastante presentes dentro de alguns lotes e, na maior parte deles, estão descobertas de vegetação, o que propicia junto ao pisoteio do gado um processo erosivo.

Uma alternativa sustentável para os variados impactos ambientais que a atividade pecuarista causa é a Integração Lavoura-Pecuária ou Sistema Agropastoril, que é definido como um sistema de produção que integra os componentes agrícola e pecuário em rotação, consórcio ou sucessão. Essa integração traz benefícios diversos para a pecuária como para o solo, pois há o processo de regeneração de pastagens degradadas.

Os impactos gerados tanto pela agricultara como pela pecuária podem ocasionar processos de degradação na paisagem do RRC. A empresa que presta serviço à Norte Energia para auxílio aos reassentados deve procurar promover mais ensinamentos sobre o uso do solo para que futuramente a paisagem que hoje eles possuem não sofra alterações mais significativas e prejudiciais.

\section{CONSIDERAÇÕES FINAIS}

A partir dos estudos iniciados no Reassentamento Rural Coletivo pôde-se perceber que a paisagem do local sofre bastante modificações, em principal o uso do solo. Antes de ser um reassentamento era uma fazenda, e nesta o uso do solo era predominantemente para fins pecuários, o que já prejudicou o solo pelo seu uso intenso. A paisagem atual é composta por dois blocos que são áreas de reserva legal e um bloco onde ficam os lotes para fins agrícolas. O uso principal do solo no local é para a agricultura, que apresenta atividade menos intensa do que a pecuária, mas mesmo assim afeta o solo se não feita adequadamente.

É possível perceber que toda essa modificação na paisagem do RRC se dá em primeiro lugar pelo fato das famílias reassentadas terem sido retiradas de seus locais de origem, onde possuíam um modo de vida diferente e acabam sendo obrigadas a modificar a paisagem para a sua sobrevivência através da agricultura e da pecuária, atividades estas que sendo em escala grande ocasionam mudanças significativas. Fazendo assim o uso de uma agricultura e pecuária sustentáveis, mas também preservando as nascentes presentes em alguns lotes, essa paisagem terá um significado de preservação pelos seus moradores. 


\section{REFERÊNCIAS}

ALVAREZ, W. P; HERRERA, J. A. Paisagem mundial na Amazônia: aportes para análise da paisagem em Altamira - PA, em decorrência da UHEBM. In. Hidrelétricas na Amazônia: Interpretações geográficas sobre as usinas no Madeira e no Xingu. Org. Maria Madalena de Aguiar Cavalcante e José Antônio Herrera. $1^{a}$ ed. pág. 159-182. GAPTA/UFPA. Belém/2017.

BECKER, B. K. Amazônia. In. As amazônias de Bertha K. Becker: ensaios sobre geografia e sociedade na região amazônica. vol. 2/ organização Imá Célia Guimarães Vieira - 1. Ed. Rio de Janeiro: Garamond, 2015.

BERTRAND, G. Paisagem e geografia física global: esboço metodológico. Caderno de Ciências da Terra, n. 13, p. 1-27, 1971.

CARPENEDO, V.; MIELNICZUK, J. Estado de agregados e qualidade de agregados de Latossolos Roxos, submetidos a diferentes sistemas de manejo. Revista Brasileira de Ciência do Solo, Piracicaba, v.14, n.1 p.99-105, 1990.

DE DEUS, R. M; BAKONYI, S. M. C. O impacto da agricultura sobre o meio ambiente. Revista eletrônica em Gestão, Educação e Tecnologia Ambiental, v(7), no 7, p. 1306-1315, mar-ago, 2012.

EMBRAPA. Centro Nacional de Pesquisa de Solos (Rio de Janeiro, RJ). Sistema brasileiro de classificação de solos. 2. ed. - Rio de Janeiro : EMBRAPA-SPI, 2006.

HERRERA, J. A. A estrangeirização de terras na Amazônia Legal brasileira entre os anos de 2003 e 2014. CAMPO-TERRITÓRIO: revista de geografia agrária. Edição especial, p.136-164, jun., 2016.

HERRERA, J. A.; SANTANA, N. C. Empreendimento hidrelétrico e famílias ribeirinhas na Amazônia: desterritorialização e resistência à construção da hidrelétrica Belo Monte, na Volta Grande do Xingu. Geousp - Espaço e Tempo (Online), v. 20, n. 2, p. 250-266, mês. 2016.

IBGE, Manuais técnico em geociências n. 7. Manual Técnico de Uso da Terra. $3^{\mathrm{a}}$ ed. Rio de Janeiro, 2013.

LENTINI, M. et al. Fatos florestais da Amazônia 2005. Belém: Instituto do Homem e Meio Ambiente da Amazônia, 2005

PORTO-GONÇALVES, C. W. Amazônia, Amazônias. São Paulo: Contexto, 2001.

SOUZA, S.R et al. Caracterização do conflito de uso e ocupação do solo nas áreas de preservação permanente do rio Apeú, Nordeste do Pará. Floresta, Curitiba, PR, v. 42, n. 4, p. 701-710, out/dez, 2012.

WÜST, C.; TAGLIANI, N.; CONCATO, A. C. A Pecuária e sua influência impactante ao meio ambiente. VI Congresso Brasileiro de Gestão Ambiental, Porto Alegre/RS, 2015. 
Recebido em: 22/10/2019

Aprovado em: 27/11/2019 